\title{
Arrow-Debreu Model versus Kornai-critique
}

\author{
By József Móczár $r^{*}$
}

\begin{abstract}
More than forty-five years have passed since János Kornai published his book entitled "Anti-equilibrium" (Kornai, 1971). This was the first scientific work in the international literature that provided a comprehensive critique on the general equilibrium theory as described in Debreu's theory of price and the Arrow-Debreu model and opened a debate on the validity of the mainstream neoclassical model. Frank Hahn's response was the most severe to the critique. Kornai, insisting on his original critique, reflected on Hahn's response in his own autobiography (Kornai, 2008). In this paper, we review the Arrow-Debreu model and its background, reconstruct the major points of the Kornai vs. Hahn debate, including its historical preliminaries, and examine the validity of criticisms and rebuttals. As we will see, the recent theories have not always verified Hahn's objections and some Nobel Prize lectures in economics recently showed that both the neoclassical theory and the general equilibrium theory in the sense of Arrow-Debreu model was wrong on either empirical or theoretical grounds (Offer and Söderberg, 2016). We also show Kornai's newest results towards an alternative model of detailed resource allocation, DRSE contrary to the general equilibrium (Kornai, 2014).
\end{abstract}

Keywords: general equilibrium theory, Arrow-Debreu model, Anti-Equilibrium, Kornai vs. Hahn debate, Walrasian equilibrium, Kornai's new equilibrium states, ex post and ex ante models, DRSE model, ergodic dynamic system.

\section{Introduction}

Although the axiomatic analysis of modern equilibrium theory, i.e., Gerard Debreu's book entitled "Theory of Value" does not explicitly discuss the Walras-model, the author, as a member of Bourbaki, does take the equilibrium theory developed from Walras' work into consideration with rigorous mathematical scrutiny (Debreu, 1959). His article co-authored by Kenneth Arrow (Arrow and Debreu, 1954) provides proof of the existence of a competitive equilibrium in a generalized abstract model. The latter could also be reduced to the Wald and Von Neumann models, which conclude a nearly two hundred years old debate. The Arrow-Debreu model had run a 'great career'. Its extensions developed in the second half of the 20th century examine externalities in production and consumption, increasing returns to scale, stochastic preferences, uncertainty, transaction structures, cost of information, the DSGE modelling approach etc. Almost all economists in the world know, use and teach it at graduate and undergraduate levels, so one might be surprised to find out that it was published after stormy preliminaries and that, even after its publication, it was heavily criticised (Weintraub, 2002). Although Weintraub (2002) failed to clarify the essential criticisms regarding

${ }^{*}$ Professor of Mathematical Economics, Corvinus University of Budapest, Hungary. 
its publication, a newly established critique came recently to light in Baumgartner's paper (Baumgartner, 2005). Additionally, Hahn and Petri (2003) include these newest problems into their book. Lately, the Nobel-prize lectures in economics strongly criticised it (Offer and Söderberg, 2016). In the Hungarian literature, its assumptions were also questioned, especially by Kornai, as we will see later.

Nicholas Georgescu-Roegen, then co-editor of Econometrica, called upon William Baumol (Department of Economics, University of Princeton) and Cecil Glenn Phipps (Department of Mathematics, University of Florida) to review the submitted article. Baumol was expected to review the paper from an economic point of view and Phipps was supposed to check the paper's mathematical correctness. However, the reverse happened; Baumol asked the authors for more in-depth examination of Nash's theorem and for correction of mathematical notations while Phipps objected to the abstract economic assumptions. Even more importantly, Baumol supported the paper's publication after corrections, while Phipps insisted on a thorough revision. The original paper was published in Econometrica in the summer of 1954, without considering the reviewers' feedback. On September 18-th, 1954, Phipps sent a letter to Robert Strotz, who was the editor-in-chief of Econometrica at that time, in which he expressed his displeasure due to the paper's publication, and explained his worries considering the model's economic assumptions. $\mathrm{He}$ wanted to publish his letter as a "Letter to the Editor" but the Editorial Board eventually voted against it. An exciting summary of the letter is included in the book of Weintraub (2002). From our point of view, it is much more interesting that neither Kornai's critique (Kornai, 1971) nor Hahn's article (Hahn, 1973) mentioned any of these events, especially the economic "problems" brought up by Phipps, which is understandable since the editorial review had been confidential for a long time.

These events motivated us to go back to János Kornai's world-famous book entitled "Anti-equilibrium" and examine his critique in a new perspective, keeping in mind Frank H. Hahn's warning: "It is not too profitable to go again through glowing embers" (Hahn, 2005). Of all the critiques, we selected Kornai's because, in his work, an elegant mathematical background supports the constructive economical approach. Also, besides his criticism, he outlined a disequilibrium model in his book, which approaches the real phenomena much better. The latter is further justified by the non-equilibrium paradigm shift in the 1990's economic theory.

Up to now, the school of disequilibrium theory has been highly respected by researchers and scholars. For example, Bénassy (2005), in his book, entitled "The Macroeconomics of Imperfect Competition and Non-clearing markets" and published by MIT Press, discusses imperfect competition and non-clearing markets instead of disequilibrium. Additionally, the book entitled "Cycles, Growth and Structural Changes", edited by Lionello Punzo (2001), deals with the disequilibrium phenomenon in the context of Schumpeterian dynamics. For example, the book features an essay by Iwai (2001), examining the disequilibrium phenomenon using his evolutionary model. The non- 
equilibrium school has become a powerful stream in economical thought since the end of the 1980's and it is regarded as extending the work of the disequilibrium school. While the disequilibrium school developed its own theory for the commodity markets, the non-equilibrium school, also included the money markets, capital markets and labour markets in its research. The latter's key feature is that it examines the behaviour of the economy when it is not in Walrasian equilibrium, similar to Kornai's asymmetrical market conditions, if they are substituted for the right dynamics. Its toolbox consists of mathematical theories and theorems dealing with nonlinear dynamic systems. Its most outstanding representatives are R. H. Goodwin, R. H. Day, K. Nishimura, J. Benhabib, T. Ito, C. Chiarella, M. Yano etc.

Kornai's critique targets the general equilibrium theory reflected in Debreu's theory of value and the Arrow-Debreu model (Kornai, 1971, p. 39.), so we do not consider the rest of specific equilibrium models such as the one developed by McKenzie (McKenzie, 1954). In the present study, the ArrowDebreu model is outlined together with its historical background, including Wald's (1935) particular models of production and consumption. We will show that unlike Wald's models, the Arrow-Debreu model features a comprehensive, theoretical representation of the production and consumption system, while it also takes into account the circular flow of incomes.

After Kornai's critique the followers of general equilibrium theory did not remain silent; the sharpest riposte was borne from the pen of Frank H. Hahn (Hahn, 1973) whose validity we will examine in the light of the developments of more than forty-five years and Kornai's auto-biography (Kornai, 2005). We examine the Kornai vs. Hahn debate, using the reconstruction method of the history of science. Following the abbreviations used by Kornai and Hahn, the $\mathrm{AE}$ stands for the anti-equilibrium and the GE for the general equilibrium theory of Arrow-Debreu. It should be noted here that Hahn was one of the foremost experts in GE, chiefly developed in his book written together with Arrow and published at the same time with the AE theory (Arrow and Hahn, 1971). In the course of evaluating the debate, we will examine the differences between $\mathrm{AE}$ and GE from a philosophical point of view, which - as we will see - does not question the relevance of either approach. However, the latest theories do not justify Hahn's objections in all cases.

\section{Preliminary Classic General Equilibrium Theories}

The general equilibrium theory dates back to classical economists: its forerunners were Smith, Ricardo, Cournot, J. S. Mill and Marx. Antoine Augustin Cournot raised the idea of the general equilibrium, as follows: “(...) in reality the economic system is a whole of which all the parts are connected and react on each other (...). It seems, therefore, as if, for a complete and rigorous solution of the problems relative to some parts of the economic system, it were indispensable to take the entire system into consideration. But this would surpass the powers of mathematical analysis and of practical 
methods of calculation" (Cournot and Fisher (1897, p. 198) quoted in Weintraub (1979, p. 19)). It should be noted that the classic economic theories cannot be considered as general equilibrium theories as they did not integrate demand into their supply-based approaches. Cournot's examination of the partial equilibrium of a single market was the first paradigm of a general theory of equilibrium, in which however, he neglected the influence of other markets. He theorised supply and demand of goods as being dependent only on price with equilibrium price being the price at which the value of supply was equal to the value of demand.

The full recognition of the idea of general equilibrium is attributed to Walras (1874), ${ }^{1}$ but the beginning of modern theoretical developments date back to Cassel (1932). Gustav Cassel published a simplified Walrasian system, which was easy to handle. According to the theorem, "(...) the pricing problem is essentially a single problem extending over the whole of the exchange economy and gives the pricing prices process an intrinsic consistency which can only be expressed by a system of simultaneous equations. " (Cassel, 1932, p.148)

According to (Weintraub, 1979), this analysis is still acceptable by modern standards too, although mathematics is not used to explore new characteristics of the system but only to ensure clarity of the discussion. General equilibrium is interpreted as:

(i) providing models of economic systems based on private property in which the interdependence of producers and consumers is determined;

(ii) revealing the decisions of economic agents made independently from each other;

(iii) formulating the role of the price system in mediating conflicting decisions of economic agents;

(iv) specifying the robustness of the schemes that solve the afore-mentioned problems.

If these criteria are accepted, it can be argued that Cassel safely managed to fulfil the first $(i)$; partly analysed the second (ii); not rigorously dealt with the third (iii); and directed the fourth to a lesser extent (iv). The majority of modern analyses and the mathematical modeling of the general equilibrium theory were developed later, in the context of the seminars held by Menger in the early 1930's in Vienna (for details, see Punzo, 1989). More specifically, Wald was the first to publish a pragmatic solution to the general equilibrium model (Wald, 1951), which satisfied each of the criteria (i)-(iv).

Wald developed a general equilibrium model regarding the production and another regarding the exchange of goods, mathematically proving the existence

\footnotetext{
${ }^{1}$ It is worthy of note that Cournot taught political economy and mathematics to Auguste Walras, who was the father of Léon Walras. Cournot's equilibrium theory is considered as one of the sources of inspiration for Léon Walras and his equilibrium theory.
} 
of equilibrium in each (Wald, 1935; 1936). ${ }^{2}$ The former, being based on the works of Walras (1874), Cassel (1932), Schlesinger (1935) and Wald's model of exchange economy, provided a qualitatively new framework for the ArrowDebreu model, with significantly weaker restrictions for production technologies and consumer preferences. It is less known that Wald's exchange model also includes the assumption of diminishing marginal utility. Since these models could contribute to understanding the more abstract Arrow-Debreu model, they are summarised below.

To set up Wald's production model, we start from the Walras-Cassel equations below:

$$
\begin{aligned}
& r_{i}=a_{i 1} s_{1}+a_{i 2} s_{2}+\ldots+a_{i n} s_{n} \quad(i=1,2, \ldots, m) \\
& \sigma_{j}=a_{1 j} \rho_{1}+a_{2 j} \rho_{2}+\ldots+a_{m j} \rho_{m}(j=1,2, \ldots, n) \\
& \sigma_{j}=f_{j}\left(s_{1}, s_{2}, \ldots, s_{n}\right) \quad(j=1,2, \ldots, n),
\end{aligned}
$$

where

$r_{i}$ - is the available quantity of the $i$-th factor of production;

$a_{i j}$ is the quantity of $i$-th factor of production to produce one unit of $j$-th product;

$s_{j}$ is the total output of the $j$-th product;

$\sigma_{j}$ is the unit price of the $j$-th product;

$\rho_{j}$ is the unit price of the $j$-th factor of production; and

$f_{j}\left(s_{1}, s_{2}, \ldots, s_{n}\right)$ is the $j$-th product's inverse demand curve.

Walras used only scarce factors of production in his model; meaning that he considered them as a priori fixed factors of the economy. However, many economists recognized, that the scarcity or abundance of a production factor depends on its demand function, its technical coefficients etc., so it can be deduced from the production function. Therefore, for example, Zeuthen and Schlesinger (1935) suggested that it is not necessary to hypothesise total use of production factors, and they introduced a new unknown $u$, denoting the surplus of the factors. It follows that the factors with positive $u$ values are free and their price $\rho$ will be zero.If, however, $u=0$ then the factor of production is scarce and its price $\rho$ is expected to be positive. Adding this hypothesis, the above equation system is changing as follows:

$$
r_{i}=a_{i 1} s_{1}+a_{i 2} s_{2}+\ldots+a_{i n} s_{n}+u_{i} \quad(i=1,2, \ldots, m)
$$

\footnotetext{
${ }^{2}$ To avoid orthodoxy we note that Wald's demonstrations - along with many other proofs from the first half of the 20th century - are still subject to research. For example, John (1999) proved the existence of general competitive equilibrium in the Walras-Cassel model using modern mathematics.
} 


$$
\begin{array}{lr}
u_{i} \rho_{i}=0 & (i=1,2, \ldots, m) \\
\sigma_{j}=a_{1 j} \rho_{1}+a_{2 j} \rho_{2}+\ldots+a_{m j} \rho_{m} & (j=1,2, \ldots, n) \\
\sigma_{j}=f_{j}\left(s_{1}, s_{2}, \ldots, s_{n}\right) & (j=1,2, \ldots, n)
\end{array}
$$

Schlesinger (1935) posed a significant research question regarding a general equilibrium equation system consisting of $2 m+2 n$ equations; whether there is a unique nonnegative solution for $2 m+2 n$ unknowns.

Wald responded to this question with the following theorem, proving that:

The equations system (1) has a nonnegative solution for the unknowns $2 m+2 n$; the solution is unique for the unknowns, $\mathrm{s}_{1}, \mathrm{~s}_{2}, \ldots, \mathrm{s}_{\mathrm{n}} ; \sigma_{1}, \sigma_{2}, \ldots, \sigma_{\mathrm{n}}$; $\mathrm{u}_{1}, \mathrm{u}_{2}, \ldots, \mathrm{u}_{\mathrm{m}}$, if

[1]. $r_{i}>0 \quad(i=1,2, \ldots, m)$;

[2]. $a_{i j} \geq 0(i=1,2, \ldots, m ; j=1,2, \ldots, n)$;

[3].For each $j$ there is at least such an $i$ for which $a_{i j}>0$;

[4]. The inverse demand function $f_{j}\left(s_{1}, s_{2}, \ldots, s_{n}\right)$ is nonnegative and continuous for all such an $n$-tuple $s_{1}, s_{2}, \ldots, s_{n}$ for which $s_{j} \neq 0(j=1,2, \ldots, n)$;

[5]. If such $n$-tuple $s_{1}^{k}, s_{2}^{k}, \ldots, s_{n}^{k} \quad(k=1,2, \ldots, \infty)$ of nonnegative numbers in which $s_{j}^{k}>0$ for all $k$, converge such a $n$-tuple $s_{1}, s_{2}, \ldots, s_{n}$ in which $s_{j}=0, \quad \lim _{k \rightarrow \infty} f_{j}\left(s_{1}^{k}, s_{2}^{k}, \ldots, s_{n}^{k}\right)=\infty,(j=1,2, \ldots, n) ;$

[6].If $\Delta s_{1}, \Delta s_{2}, \ldots, \Delta s_{n}$ are such that among them there is at least one negative number and

$$
\text { if } \sum_{j=1}^{n} \sigma_{j} \Delta s_{j} \leqq 0 \text {, then } \sum_{j=1}^{n} \sigma_{j}^{\prime} \Delta s_{j}<0 \text {, }
$$

where $\sigma_{j}^{\prime}=f_{j}\left(s_{1}+\Delta s_{1}, s_{2}+\Delta s_{2}, \ldots, s_{n}+\Delta s_{n}\right),(j=1,2, \ldots, n)$.

[7]. The rank of matrix $\left\lfloor a_{i j}\right\rfloor$ is $m$.

Wald's exchange economy contains $n$ agents, $m$ commodities and an initial amount of commodities, owned by the $i$-th agent, denoted by $a_{i j}(j=1,2, \ldots$, $m$ ). $\Delta a_{i j}$ stands for $i$-th agent's nature of transaction regarding $j$-th commodity: if $\Delta a_{i j}>0$, then it shows demand while, if $\Delta a_{i j}<0$, then it reveals supply. It is assumed that points located on the well-behaving indifference-surfaces represent preferences. If, for the sake of simplicity $x_{1}, x_{2}, \ldots, x_{m}$ denote the quantities of each commodity in Wald's specification $x_{j}=a_{i j}+\Delta a_{i j}$ and $U_{i}$ denotes the utility of $i$-th agent, then the marginal utility function is defined as follows: 
$f_{i j}\left(x_{1}, x_{2}, \ldots, x_{m}\right)=\lambda_{i}\left(x_{1}, x_{2}, \ldots, x_{m}\right) \frac{\partial U_{i}\left(x_{1}, x_{2}, \ldots, x_{m}\right)}{\partial x_{j}}$,

where $j=1,2, \ldots, m$ and $\lambda$ is a proportionality factor.

The change in the equilibrium is defined by the conditions, which ensure maximal utility for all agents. The latter include unit prices of goods, relationships among the marginal ratios for all goods and agents (namely, price and marginal utility ratios), individual budget constraints, i.e., $p_{1} \Delta a_{i 1}+p_{2} \Delta a_{i 2}+\ldots+p_{m} \Delta a_{i m}=0,(i=1,2, \ldots, n)$, and restrictions of supply and demand equality, i.e., $\Delta a_{1 j}+\Delta a_{2 j}+\ldots+\Delta a_{n j}=0,(j=1,2, \ldots, m)$.

Then, Wald made the following statement: the exchange equations have at least one solution for the relative prices $p_{1}, p_{2}, \ldots, p_{m}\left(\mathrm{p}_{1}=1\right)$ and $\Delta a_{i j}$ for all $i, j$ index pair, under the restrictions $p_{j}>0$ és $a_{i j}+\Delta a_{i j} \geqq 0$, if

1. $a_{i j} \geqq 0$ for all $i, j$ (each agent has nonnegative stock);

2. $\sum_{i} a_{i j}>0$ for all $j$ (there is positive stock from each good);

3. $\quad \sum_{j} a_{i j}>0$ for all $i$ (each agent has positive capacity);

4. $f_{i j}\left(x_{1}, x_{2}, \ldots, x_{m}\right)$ is equal to $f_{i}\left(x_{1}, x_{2}, \ldots, x_{m}\right) \varphi_{i j}\left(x_{j}\right)$ for all $i, j$ where $f_{i}$ is not a zero function and $\varphi_{i j}$ is a continuous monotone decreasing function, with this last condition concerning diminishing marginal utility.

Wald (1936/1951, p. 384) argues that "conditions [1] to [4], which prove the solubility of the equations of exchange, agree substantially with the Walrasian assumption. Thus, Walras is correct in asserting the solubility of these equations of exchange. However, this can only be proven with the aid of recondite methods of modern mathematics, and the method Walras uses to attempt to prove the existence of equilibrium prices is completely inadequate."

Although widely accepted among economists that Wald solved the general equilibrium problem formulated by Walras and Cassel, it was not clear for them that such a system has any significant economic essence. In fact, Keynes (1936) suggested that the analysis of aggregated supply and demand has its roots in the traditional theory of value since economy exists in historical time. Patinkin (1948) was the first to suggest that the formalized apparatus of the general equilibrium should include a constant coefficient of technology and money. However, Keynes' monetary theory of production was hardly compatible with this approach and only a handful of economists thought that such a comparison could be interesting.

The only other model that dealt with the existence of a unique solution to the general equilibrium models was Von Neumann's economic growth model, developed in early 1930's. Von Neumann and Morgenstern (1945) examined 
an economy in which the factors of production are not limited, it has constant return to scale, it produces $n$ goods and its technology consists of $m$ activities. The model's equilibrium solution depends on intensity ratios of activities, the economic growth rate, and the interest rate. A number of economic assumptions ensure the existence of a balanced growth path (as described in Móczár (1995)). The model produced substantial developments at least in three areas: in the design of production models of activity analysis; in the theory of the non-aggregated capital; and in proving the existence of competitive equilibrium (for comparisons of Cassel's, Wald's and Von Neumann's models see Punzo (1991).

Hicks (1939) was the first to support the stability of the Walras model. He formulated the following assumptions concerning the equilibrium:

$D_{i}\left(p_{1}, p_{2}, \ldots, p_{n}\right)-S_{i}\left(p_{1}, p_{2}, \ldots, p_{n}\right)=0 \quad i=1,2, \ldots, n$,

Or, alternatively

$E_{i}\left(p_{1}, p_{2}, \ldots, p_{n}\right)=0, \quad i=1,2, \ldots, n$,

where $p_{i}$ is the unit price, $D_{i}, S_{i}$ and $E_{i}$ are the demand, supply and excess demand of the $i$-th commodity respectively. Hicks (1939, pp. 315-316) used the Jacobian matrix from the excess demand functions

$\left(\frac{d E_{i}}{d p_{j}}\right), \quad i, j=1,2, \ldots, n$,

to show that the equilibrium is expected to be stable, if the principal minors of the Jacobian matrix have alternating signs at the equilibrium price:

$$
\operatorname{det}\left(\frac{d E_{1}}{d p_{1}}\right)<0, \operatorname{det}\left(\begin{array}{ll}
\frac{d E_{1}}{d p_{1}} & \frac{d E_{1}}{d p_{2}} \\
\frac{d E_{2}}{d p_{1}} & \frac{d E_{2}}{d p_{2}}
\end{array}\right)>0, \text { etc. }
$$

Without relying on any controlling tool, the model's criterion was only dependent on the excess demand functions; that is, in the case of a single market, the supply curve must be steeper than the demand curve in the equilibrium point.

Samuelson's stability analysis eliminated the deviations from the equilibrium path by using the dynamic laws of motion, i.e., and introducing an autonomous differential equation system simulating the method of tatonnement: 


$$
\frac{d p_{i}}{d t}=k_{i} E_{i}\left(p_{1}, p_{2}, \ldots, p_{n}\right)=0, \quad i=1,2, \ldots, n,
$$

which states that the changing rate of the $i$-th unit price is proportional to the excess demand in the $i$-th market (Samuelson, 1943; 1947). ${ }^{3}$ This statement contains two important premises. The first is that the unit prices are not affected by demand or supply but they are rather given. This price taking behaviour is the cornerstone of competitive equilibrium. The second statement is that the unit price is only a parameter in the market. Agents adjust their demand and supply every given moment under the given prices, without being able to influence price levels. Price adjustment is assumed to be instantaneous.

Samuelson came up with the necessary and sufficient conditions of stability for the linear case (Samuelson, 1947). To demonstrate this, the system describing the tatonnement method is described below:

$$
\frac{d p_{i}}{d t}=k_{i}\left(a_{i}+\sum_{j} b_{i j} p_{j}\right), \quad i=1,2, \ldots, n,
$$

which can be rewritten in the form of a matrix equation:

$$
\frac{\mathbf{d p}}{\mathbf{d t}}=K \mathbf{a}+K \mathbf{B} \mathbf{p}
$$

where $\mathbf{p}=\left(p_{1}, p_{2}, \ldots, p_{n}\right)^{T}, K=\operatorname{diag}\left(k_{1}, k_{2}, \ldots, k_{n}\right), \mathbf{a}=\left(a_{1}, a_{2}, \ldots, a_{n}\right)^{T}$ and $\mathbf{B}=\left(b_{i j}\right)$. Samuelson used $K=\operatorname{diag}(1,1, \ldots, 1)$ to show that, in this case, the Walrasian equilibrium is stabile if and only if the real parts of the eigenvalues of matrix $B$ are negative. While Hicks's criterion for stability has an economic meaning, since the principal minors of the appropriate Jacobian matrix with alternating signs serve as sufficient conditions for some optimization problem, Samuelson's criterion lacks such a meaning. Smithies was the first, who showed that the eigenvalue-based criterion also has an economic meaning (Smithies, 1942). Later, Metzler showed the equivalence of the two criterions under different conditions (Metzler, 1945). For example, if $K=\operatorname{diag}(1,1, \ldots, 1)$, then Hicks' definition contains Samuelson's one, while if all commodities are strongly gross substitutable (i.e., $d E_{i} / d p_{j}>0, i \neq j$ ), Hicks' definition is equivalent to Samuelson's.

\footnotetext{
${ }^{3}$ It should be noted that according to Bródy the excess demand influences directly the acceleration of prices, $\ddot{p}(\mathrm{t})$, instead of change rate of prices. In this case, the modified differential equation above describes a harmonic oscillator (Bródy, 1980).
} 


\section{The Arrow-Debreu Model of General Equilibrium}

The modern phase of the general equilibrium theory started in 1954 when Arrow and Debreu (1954) remodelled Wald's system and substituted the sets of production and consumption preference structures for the fixed coefficients of production technology and the marginal utility function, respectively. They started from the assertion that the competitive equilibrium should be Paretoefficient and that all Pareto-efficient allocations should be viewed as potential competitive equilibrium points. Therefore, the social activities promoting efficiency should examine the existence of equilibrium levels in competitive economies.

In their definition, the set of vectors $\left\{x_{1}^{*}, x_{2}^{*}, \ldots, x_{m}^{*}, y_{1}^{*}, y_{2}^{*}, \ldots, y_{n}^{*}, p^{*}\right\}$ represents a competitive equilibrium if they satisfy the following conditions:

[1]. $y_{j}^{*}$ maximizes $p^{*} y_{j}$ for all $j$ over the set $Y_{j}$;

[2]. $x_{i}^{*}$ maximizes the utility function $u_{i}\left(x_{i}\right)$ on the set:

$\left\{x_{i} \mid x_{i} \in X_{i}, p^{*} x_{i} \leq p^{*} \zeta_{i}+\sum_{j=1}^{n} \alpha_{i j} p^{*} y_{j}^{*}\right\}$

[3]. $p^{*} \in P=\left\{p \mid p \in R^{l}, p \geq 0, \sum_{h=1}^{l} p_{h}=1\right\}$;

[4]. $z^{*} \leq 0, p^{*} z^{*}=0, z=x-y-\zeta$ and $x=\sum_{i} x_{i}, y=\sum_{j} y_{j}, \quad \zeta=\sum_{i} \zeta_{i}$.

It should be noted that Arrow and Debreu took over the notation of vector ordering from game theory and provided the economic meaning of each vector:

- $x \leqq y$ means that $x_{h} \leqq y_{h}$ for all $h$;

- $x \leq y$ means that $x_{h} \leqq y_{h}$, but $x \neq y ; x<y$ means that $x_{h}<y_{h}$ for all $h$;

- $y_{j} \in Y_{j} \subset R^{l}$ and if $y_{h j}>0$, then it is output, if $y_{h j}<0$, then it is input, and $R^{l}$ denotes an Euclidean space with $l$-dimension;

- $x_{i} \in X_{i} \subset R^{l}$ and if $x_{h i}>0$, then it is consumption;

- if $x_{h i}<0$, it is the supply of $h$-type of work (negative consumption);

- $\quad \zeta_{i}$ is the stock of $i$-th consumer and $\alpha_{i j} \geqq 0$ is the share of $i$-th consumer from the profit of $j$-th product. Furthermore

- $\Omega=\left\{x \mid x \in R^{l}, x \geq 0\right\}$ is a non-negative orthant.

The following assumptions ensure the existence of equilibrium:

a) $Y_{j}$ is a closed convex set for all $j=1,2, \ldots, n$ (there is no increasing return to scale);

b) $0 \in Y_{j}$ is for all $j$ (the idleness is also an activity);

c) $Y\left(=\sum_{j} Y_{j}\right) \cap \Omega=\{0\}$ (without input is impossible to produce anything); 
d) $Y \cap\{-Y\}=\{0\}$ (the activities are irreversible, i.e., the possibility of two such production vectors equalizing each other is excluded; in other words, the outputs of one of them precisely equals the inputs of the other) ${ }^{4}$

e) $X_{i}$ is a non-empty, closed and limited set, or there is such $\xi_{i}$, for which $\xi_{i} \leqq x_{i}(i=1,2, \ldots, m)$ is satisfied for all $x_{i} \in X_{i}$.

f) $u_{i}\left(x_{i}\right)$ is a quasi-concave continuous function showing that the indifference surfaces are convex, given that the set $\left\{x_{i} \mid x_{i} \in X_{i}\right.$ és $\left.u_{i}\left(x_{i}\right) \geq \alpha\right\}$ is convex for any fixed number $\alpha ;^{5}$

g) $u_{i}\left(x^{\prime}\right)>u_{i}(x), \quad x^{\prime} \in X_{i}$ (the consumers are always unsatisfied as for every consumer basket there is always a better consumer basket); ${ }^{6}$

h) $\sum_{i} \alpha_{i j}=1$ for all $j$ (the all produced profit is distributed);

k) $\zeta_{i} \in R^{l}$; and for some vector $x_{i} \in X_{i}$ the relation $x_{i}<\zeta_{i}$ is satisfied (inventory capacity which ensures the surviving or in other words that is the assumption of active autarchy). ${ }^{7}$

Arrow and Debreu proved the existence of equilibrium in competitive models using Nash's concept of equilibrium for non-cooperative games with $n$ agents. According to Nash's definition, all agents maximize their gains while they take the other agents' action in equilibrium as given (Nash, 1950).

The proof of equilibrium existence is schematically the following: Each of the $m$ consumers selects a vector $x_{i}$ from the $X_{i}$ set satisfying the condition that in this vector, $x_{i} \in A_{i}\left(\bar{x}_{i}\right)^{8}$ they get $u_{i}\left(\mathrm{x}_{\mathrm{i}}\right)$ gains. The $j$-th of the $n$ producers chooses a vector $y_{j}$ from $Y_{j}$, which is not restricted by the action of others, and gets $p y_{i}$ in return; finally the last player, the market, chooses a price $p$ from the $P$ set and gets $p z$ income in return. Informally, every consumer makes a restricted consumption choice and gets a provisional utility payment leading to demand of products and supply of production factors. Similarly, every firm makes a restricted decision about the input-output ratios leading to provisional profit and decides supply of goods and demand of factors bundles. A fictive market-organizer chooses the market prices, under which the interplay between market demand and supply takes place in the markets where agents act. The latter react to the prices chosen by the organizer who sets the market prices and all agents act in accordance with them, their actions leading to efficient supply and demand. The organiser compares demand and supply and adjusts the prices

\footnotetext{
${ }^{4}$ It should be mentioned that Arrow and Debreu took over the concept of irreversibility from (Koopmans, 1951, pp. 48-50.).

${ }^{5}$ The authors draw the readers' attention to the applicability of a stronger requirement, namely to the strictly quasi-concave utility function. (Arrow and Debreu, 1954, p. 26)

${ }^{6}$ This assumption can be weakened. (Arrow and Debreu, 1954, p. 25)

${ }^{7}$ The invalidity of this assumption is also admitted by the authors but it is necessary for the proof of equilibrium existence.

${ }^{8}$ Now, $A_{i}\left(\bar{x}_{i}\right)=\left\{x_{i} \mid x_{i} \in X_{i}, p x_{i} \leq p \zeta_{i}+\max \left\lfloor 0, \sum_{j=1}^{n} \alpha_{i j} p y_{j}\right\rfloor\right\}$.
} 
gradually to market clearing. If this process always leads to demanded and supplied goods and factors taking the same price, this final price is the equilibrium price. In other words the equilibrium price, if it exists, mediates the conflicting interests of the agents, who no longer desire to take any further action.

This justification of the equilibrium existence requires acceptance of the assertion that the equilibrium is a set of such combinations of prices and quantities to which the agents have no objection. The supply-demand balance serves as a mechanism, which helps the agents to compare their preferences to see whether they meet. Semantically, the argument is not that "the equilibrium is a balance of supply and demand" but rather that "in equilibrium, the supply and demand are well balanced". While (iii) and (iv) conditions are necessary for the equilibrium to exist, conditions (i)-(iv) are the sufficient and necessary conditions. In the Arrow-Debreu model, the coordination of the agents' plans through optimization is necessary for the market clearing equilibrium.

Moving to the modern economic approach to the stability of competitive equilibrium, the basic model developed by Negishi (1962) is described below:

If the market of the $i$-th factor or good follows a tatonnement process, then the price of the $i$-th commodity moves together with its excess demand, and the excess demand is dependent on the prices of all $n$ commodities under unit adjusting velocity:

$$
\dot{\mathrm{p}}_{\mathrm{i}}=E_{i}\left(p_{1}, p_{2}, \ldots, p_{n}\right), i=1,2, \ldots, n \text {. }
$$

It is assumed that the excess demand function is continuously differentiable, of zero degree, homogenous and satisfies Walras' law. So if $p=$ $\left(p_{1}, p_{2}, \ldots, p_{n}\right)$ and $E=\left(E_{1}, E_{2}, \ldots, E_{n}\right)$, then $\sum p_{i} E_{i}(p)=0$ ( or in vector notation $\mathbf{p E}(\mathbf{p})=0)$. Additionally, it is assumed that the price vector in the equilibrium is $p^{*}=\left(p_{1}{ }^{*}, p_{2}{ }^{*}, \ldots, p_{n}{ }^{*}\right)$ and the following function is defined: $V(p)=(1 / 2) \sum\left(p_{i}-p_{i}^{*}\right)^{2} . V(p)$ is an Euclidian measure of distance of the real price's deviation from the equilibrium price. $V$ is a Lyapunov function, a continuously differentiable function of the state variables (the prices). It is nonnegative, and zero if and only if the state is in equilibrium (Lyapunov, 1907).

$V$ is differentiated with respect to time to see whether the system's state variables approach the equilibrium along the supply and demand trajectories. This is reflected in:

$$
\dot{V}=\sum \dot{p}_{i}\left(p_{i}-p_{i}^{*}\right)=\sum p_{i} E_{i}-\sum p_{i}^{*} E_{i}=-\sum p_{i}^{*} E_{i}
$$

where the last equation is satisfied because of Walras' law. Thus, the question is whether excess demand weighted by the equilibrium prices is positive. Since the work by Arrow, Block and Hurwicz, (1958; 1959), modern mathematical 
proofs have been dependent on gross substitutability and homogeneity with zero degree, ensuring the positivity of the last expression which in turn makes

it obvious that the Lyapunov function is monotonously decreasing as $V<0$. This also proves that the equilibrium of a pure exchange economy with the above conditions is globally stable.

In the 1940's and 1950's, the authors of early works on the stability of the Walrasian system thought that stability can be extended to a broader class of the general equilibrium models. However, the new developments overshadowed this optimism. At first, Scarf's paper (1960) then Gale's book (1973) proved that equilibrium could be unstable in much simpler Walrasian models with fewer goods and economically sound assumptions. Particularly, this instability arose in Scarf's counterexample where he examined a special complementary-type model of three commodities and three consumers. Gale's counterexample showed that:

$$
\begin{aligned}
& \dot{p}_{1}=\lambda_{1} E_{1}\left(p_{1}, p_{2}\right) \\
& \dot{p}_{2}=\lambda_{2} E_{2}\left(p_{1}, p_{2}\right)
\end{aligned}
$$

The price fluctuation mechanism of two commodities will always be unstable under certain $\lambda_{1}$ and $\lambda_{2}$ values of the adjusting velocities and if one of them is a Giffen-good $\left(\partial E_{i} / \partial p_{i}>0\right.$ for one $i$ ). These counterexamples convinced the majority of economists that the global stability is rather a special case than a general characteristic of the Walrasian model of general equilibrium. As we will later show this conviction was reinforced by the Debreu-Sonnenschein-Mantel results in the early 1970's, regarding the nature of aggregated excess demand functions.

In the next section, we will examine the criticisms to Arrow-Debreu model, followed by Hahn's (1973) rejection, examined in the light of current findings.

\section{Kornai's vs. Hahn's Critiques}

Kornai's critique of the general equilibrium theory is primarily based on his doubts considering the validity of the general equilibrium assumptions. As Weintraub (1979) argues that "Kornai sees the deficiency of the general equilibrium theory" in that "the category of phenomena which can be even approximately described by the set of twelve basic assumptions is extremely restricted. The conceptual apparatus is similarly narrow (...) [it] offers little explanation of the real motion of the economy" (Kornai, 1971, p.30). In supporting his model developed in 1971, Kornai (1971) argues that these assumptions contradict the reality of the markets; that the lack of information dissemination and control points in a hierarchical economy can be misleading; and that the lack of institutional details of how modern economies actually 
allocate resources in a non-competitive market mechanism is simply outrageous.

According to Weintraub (1979), the fundamental critique comes from Kornai's methodological standpoints as he adopted the view that "for the description of the economic system, mathematical economics has succeeded in constructing a formalized theoretical structure, thus giving an impression of maturity, but one of the main criteria of maturity, namely, verification, has hardly been satisfied. In comparison to the vast amount of effort which has been applied, up to now, in checking the assumptions and statements seems inconsequential." (Kornai, 1971, p.17)

However, Hahn's (1973) critique has inveighed sharply against the antiequilibrium (AE) theory. His primary problem with Kornai's critique was that his toolbox lacks the epistemological approach rooted in the philosophy of science. As Hahn (1973) claims, that is why he gets the synthesis of neither the deductive logical system based on axiomatic (Bourbaki) foundations (GE) nor the deductible practical conclusions based on the evaluation of the results. He sees the GE as being a "merely an intellectual experiment" (Hahn, 1973, p.323), missing its enormous practical significance. At the same time, Hahn (1973) recognizes that there is truth in the observation "that the GE has not done more than codify nineteenth century economics". It is interesting to see that even Hahn of the Cambridge University cannot accept Kornai's - quite factual - critique, that the price cannot be the only information on which the equilibrium is based since the output, the stockpile, and the government's measures also play an important role in the process. However, this criticism could be partly attributed to the fact that Hahn could not had known ${ }^{9}$ the difference between the Walrasian price adaptation in exchange theory and the Marshallian quantity adaptation in the context of the production theory. The former takes place instantaneous under fixed quantities of products in an exchange economy while the latter needs a short amount of time under fixed prices of factors in the production process. These processes require two different approaches: in the former, the price is adjustable while in the latter, the quantity is the independent variable. Naturally, both processes can lead to the same equilibrium but their stability might differ; that is, they might have such equilibrium solutions that are stable under the Walrasian approach but that are unstable under the Marsallian framework. The existence of clearance sales somewhat justifies Kornai's assumption regarding the nonexistence of equilibrium prices, while the Marshallian instability can serve as the basis for the theory of disequilibrium.

It is well known that prior work on the general equilibrium (GE) theory contains a number of logical inconsistencies. The GE concept is too complicated and general, with the role of quantities being identical to that of

\footnotetext{
9 At that time, Mas-Collel's (1986) achievements were still unknown. In his cross-dual model, Mas-Collel examined the Walrasian adjusting processes together with their Marshallian counterparts, that lead, in some cases, to cyclical changes of the quantity and the price, a type of limit cycle on which the economy calms down. Kornai's definition of equilibrium can be considered as a forerunner of this model.
} 
qualities etc. Hahn himself also knew this as it seems he could not find a grip on Kornai's empirical interpretation of preferences and thus, had accepted with a reconcilement that Kornai's objections regarding the relative stability of preferences were valid. However, he hastily added that the specification of stochastic preferences is still controversial ${ }^{10}$ just as the application of nonconvex preferences. He tried to resolve Kornai's scepticism relating to the role of the optimizing agent in the GE process by using the weaker explanation of Darwinism, citing Sidney Winter's argument that “(...) the adaptive and nonoptimizing responses of agents will be weeded out by the competitive selection process to leave only the optimizing survivors" (Hahn, 1973, p. 327).

Further, Hahn fiercely opposed Kornai's statement that the markets with excess supply are never clearing, a process that cannot be defined clearly in the context of the GE theory, as it does not distinguish between actual and intended market transactions. The argument between Kornai and Hahn about this issue can be traced back to their acceptance (or decline) of the assumption of perfect foresight. ${ }^{11}$ Nevertheless, the GE is a static model and thus, it cannot take the perfect foresight hypothesis into account. Finally, Hahn considered the GE as a theoretical framework and not as a description of the actual economy. He supported this standpoint with such vehemence that he failed to note that his explanation of equilibrium reduces the general validity of GE. He even argued that, when relevant circumstances change, the "Arrow-Debreu equilibrium becomes a special case of this general type" (Hahn (1973, p. 329) ${ }^{12}$ He also opposed Kornai mixing up the Debreu's theorem with the theory of GE. The latter rigorously examines the interaction between agents and this is what separates it from Marxist, Marshallian and empirical economics.

In the meantime, new breakthroughs emerged related to Debreu's (1959) theories, being discussed by Weintraub (2002). According to Weintraub, problems related to these theories, although multi-layered, are in essence quite similar and related to the Bourbakism. The Bourbaki School assumed that all fundamental structures share a unifying characteristic, but never actually defended this assumption. Young Debreu appeared on the stage of mathematical economics to prove that the Walrasian theory of equilibrium has the same privileged structural status, as the sets have among algebraic structures or as order relation has among topological structures. Later, both Debreu and the new generation of mathematical economists, raised on his high standards, concluded that this assumption was problematic; a discussion chiefly

\footnotetext{
${ }^{10}$ Hicks expressed it as follows: "Now the reason for this sterility of the Walrasian system is largely, I believe, that he did not go on to work out the laws of change for his system of General Equilibrium. He could tell what conditions must be satisfied by the prices established with given resources and given preferences; but he did not explain what would happen if tastes or resources changed." (Hicks,1939, p. 61)

${ }^{11}$ It should be noted here that one of Hahn and Solow's (1997) most important endeavours in later times was to accept Kornai's preferences against the absurdity of rational expectations and Lucas' macroeconomics.

${ }^{12}$ An interesting experiment of this formulation we can find in Day's (1984) paper on the dynamic GE.
} 
depicted in the Debreu-Sonnenschein-Mantel (DSM) theorem, the significance of which came to be generally accepted in the 1980's.

First, Sonnenschein $(1972 ; 1973)$ explained his concerns in two articles. The former of his articles was followed by Debreu's (1972) and Mantel's (1974) work on excess demand functions. They all started from the assumption that market demand and excess demand functions can be defined on the basis of aggregated consumers' utility maximizing actions. All three authors argue that the aggregated, market demand and excess demand functions, on which the intuitive statements of market microeconomics and macroeconomics are based, are not quite similar to individual demand and excess demand functions. ${ }^{13}$ More simply put, even if all individual demand functions behave as expected, it cannot be asserted that the aggregated, market function will behave in a similar manner. Only in very special cases, the economy is expected to behave as if consisting of ideal consumers. ${ }^{14}$ This had a marked effect on the micro-foundation of economic theory, describing the formation of market demand and supply as a simple aggregation of the behaviours of individual market agents maximising their utility. So, in essence, the last century's efforts to establish the aggregated demand adopting a utility maximizing approach were proved to be problematic. ${ }^{15}$

Another problem was the phase lag between mathematical and economic disciplines. By the 1970's, total disillusionment with Bourbakism was obvious, but thorough examination of classic economic models only started in the 1990's. When Debreu was studying the Boorbakism principles in the 1940's he could not have foreseen how the structural program of Bourbakism would end up by the 1960's. This might be helpful to understand the modest tone of his last memoirs regarding the role of mathematics in theoretical economics. "Before the contemporary period of the last five decades, theoretical physics had been the inaccessible ideal towards which economic theory sometimes strove. During that period, this striving became a powerful stimulus in the mathematicisation of economic theory. ( ... ) In these directions, economic theory could not follow the role of models offered by physical theory. Being denied a sufficiently secure experimental base, economic theory has to adhere to the rules of logical discourse and must renounce the facility of internal inconsistency" ((Debreu, 1991, p. 17.) as quoted by Weintraub (2002, p. 124)).

13 It might be interesting to mention that Hildenbrand (1983) identified the necessary distribution of individual characteristics that makes the aggregated function as it were an individual demand function.

${ }^{14}$ The assumption, that the agents of economy follow a typical pattern in their behaviour was an essential step for economics to acquire a scientific basis and methodology. Typical patterns in economic behaviour were introduced into economics by a rather simple approach: the rationality of a typical agent consists of maximising his utility under the given circumstances which often but not in every case lacks psychological and sociological considerations. It should be noted that the approach of philosophy of science taking into account psychological and sociological considerations is due to John Stuart Mill who developed David Hume's theorem on the causal nature of association processes, and firmly believed that the psychology is the foundation of social sciences. (Modern representatives of this approach are the Nobel laureates Khanemann and Smith.)

${ }^{15}$ An excellent summary of the topic can be read in Schafer and Sonnenschein (1982). 
As he himself noted many times, Debreu was never interested in describing the dynamics of an economy converging to the Walrasian equilibrium. In his monograph, written in 1958, he stresses the assumption of certainty; it is assumed that all producers know all future production possibilities. Similarly, consumers know all possible consumer options. But the issue of change could not be avoided forever, especially when the concept of dynamics was redefined to interpret the idea of stability in the circles of mathematical economists. In this context, Sonnenschein raised the following question: "Do the basic structures of the models of Walrasian general equilibrium theory comprise any constraints on the uniqueness and stability of the equilibrium states?" Apart from some trivial and unnecessary restriction, his answer was apparently negative. Werner Hildebrand, one of Debreu's German promoters formulated that effect which produced by the above answer ${ }^{16}$.

Hahn's riposte to Kornai's critique is interesting and suggestive because it evaluates the $\mathrm{AE}$ from many viewpoints. It stresses the fact that Kornai's critique suggests that scientific abstractions and analyses cannot move away from the reality too far and that the assumptions and models should be empirically verifiable and interpretable. This approach is drastically different from Milton Friedmann's tenet, according to which the forecasts are more important than the assumptions. Kornai does not prescribe an obligatory order between the data collecting and analysis and the formulation of a theoretical model and he accepts the benefits of empirical conclusions derived from calibrating a theoretical model. Kornai mainly considers the economy as a system, linking it to cybernetics and system theory. He does not focus on whether the mathematical analysis and empirical calculations used by Debreu and his followers are sufficiently developed or not. ${ }^{17}$ It should be mentioned that the theory of AE originates from the classical economics, while the GE comes from Wald's and Von Neumann's models. Kornai is obviously not satisfied with the neoclassical economists' explanation as they advocate their ex ante models as reference points in the investigation of real economic

\footnotetext{
16 "When I read in the seventies the publication of Sonnenschein, Mantel and Debreu on the structure of the excess demand function of an exchange economy, I was deeply consternated. Up to that time I had the naive illusion that the microeconomic foundation of the general equilibrium model, which I had admired so much, does not only allow us to prove that the model and the concept of equilibrium are logically consistent, but also allows us to show that the equilibrium is well determined. This illusion, or should I say rather this hope, was destroyed, once and for all, at least for the traditional model of exchange economies. I was tempted to repress this insight and continue to find satisfaction in proving existence of equilibrium for more general models under still weaker assumptions. However, I did not succeed in repressing the newly gained insight because I believe that a theory of economic equilibrium is incomplete if the equilibrium is not well determined" ((Hildenbrand, 1994, ix) quoted in Weintraub (2002, pp. 124-125))

${ }^{17}$ that is to answer Cournot's question in its complexity
} 
problems - or as Hahn puts it "in confrontation with reality" - from which descriptive theories could be developed. ${ }^{18}$

After more than 30 years, Kornai $(2005 ; 2008)$ returned to Hahn's critique. As Hildenbrand's quotation suggests, the validity of the AE theorem is not yet verified. Kornai admits that, considering the present level of economics, the explanation of $\mathrm{AE}$ does not constitute an appropriate logical unity while a number of redundant concepts and relationships often lead too far from its main message. Further, other weaknesses of Kornai's critique are the following. Firstly, his book lacked in resounding economic rhetoric in the sense that the grouping of its ideas and reasoning was not definitive enough, using neither Lakatos' (1981) method of proof, nor the logical-philosophical approach of Wittgenstein (1992). Additionally, it did not develop a new theory and most of its claims were based on introspection (Kornai, 2008, p.204). Further, it is clear from his autobiography that Kornai could not accept Marxism and the theory of neoclassical economics because both theoretical models do not highly value the empirical verification of their hypotheses and expectations. This led him back then and leads him today to the critical review of GE. His main objection is that the GE theory does not answer any of the important questions, does not help to understand the capitalistic economy more deeply and does not contribute to 'improving' the world.

Kornai compares the GE model with the Kornai-Lipták model (Kornai and Lipták, 1965). In the former, there are equal decentralized operators and the price carries the market information while in the latter, the state gives quantitative directive rules to its subordinates who are expected to obey them. Equilibrium and optimal solution exist in both models. The competitive spirit and the decentralization of information result in a boost to capitalism, contrary to socialism where information is centralized and there is no competition.

Kornai corrects his previous fallacies of theory of science by admitting that instead of criticizing the theoretical clarity of GE he should have focused on the neoclassical school. We can accept Kornai's arguments, however, the Gerard Debreu's methodology of Bourbaki is at least such an important issue. In Debreu's theory of value, there is no room for failures or uncertainties. In the light of this statement, we must agree with Kornai's objections contrary to Bourbaki mathematical school and its axiomatic analytical method since they would have strengthened the persuasive power of the critique explained in AE.

Kornai now puts more emphasis on recurring and non-recurring, as well as the comparable and non-comparable decisions. While for the formers' analysis, he finds the neoclassical model of preference formation being useful regarding the latter he argues that the rational decision model of the GE is unusable. Henceforward, he claims that historically, there has been confusion regarding the theory of equilibrium, resonates with Hildenbrand's concerns quoted above. The neoclassical school adopted the concept of "market equilibrium" in a positive manner similar to that of natural sciences. Kornai distinguishes two

${ }^{18}$ Or as Kornai (2008) put it: "Exponents claim to have a universal explanatory model of human behaviour on their hands, able to describe anything - not just narrowly economic decisions but all problems of choices, from divorce and family size up to parliamentary votes." 
types of equilibrium in the market of sellers and in the market of buyers instead of a single point where supply meets demand. In the sellers' market, excess supply is permanent while in the buyers' market the same happens with excess demand. As we have seen in the examination of stability in a purely exchange economy, the positivity of excess demand calculated using the equilibrium prices ensures the monotonically decreasing characteristic of the demand function and thus, stability, if using Lyapunov functions under the right conditions. This should not be deceiving however, since Kornai is talking about lasting excess demand and lasting excess supply. In this case, the stationary state is not an equilibrium state, and that requires a different methodology and model formulation. According to Kornai's theory, the buyers' market can never reach a state of equilibrium in the physical sense because of the lasting excess demand.

Kornai published his AE theory in 1971, while he conducted his research mainly in the last third of the 1960's. At this time, both the East and the West enjoyed an economical boost and soaring developments, while the turnpike type of research stood in the center of both theoretical and empirical economic interest (Makarov and Rubinov, 1977; Tsukui and Murakami, 1979; Móczár and Tsukui, 1992). In these new models, the dynamic concept was firstly introduced by expanding the static state in time. The static GE fitted perfectly into this line of research. Strictly speaking, Kornai went up against this dominant approach when he refuted the standard (neoclassical) static equilibrium and introduced his asymmetric states.

The examination of cycles and nonlinear trajectories in general started only after the currency crises in the early 1970's and after the oil crises of 1973 and of 1979. At the same time, there were rapid developments in the mathematical theory of dynamics. The shift was very cautious and slow. A quite representative example of these developments is the Dornbush model that adopted comparative static approaches to examine currencies (Dornbush, 1976). Hicks (1989) also admitted in his last book that the stable fixed-point paradigm project was outdated. By the 1990's, deriving a static economic (equilibrium) model or Nash-equilibrium from a non-equilibrium dynamics has already been almost a routine exercise (Chiarella and Flashel, 2000).

In this asymmetry, the driving force of capitalism was the competition in non-equilibrium state, which led to innovation, technical development and the market introduction of new consumer goods. ${ }^{19}$ The other asymmetry gives the true equilibrium state in socialism, which is examined by Kornai (1980) in his other worldwide known book entitled "Economics of Shortage". There, he argues that the neoclassical economic equilibrium is just an illusion just like the Einsteinian thermodynamic irreversibility in physics; even, Walras himself considered the former only as an ideal state.

19 “My book (...) [is] central to Schumpeter's theory: technical advance and continual innovation are the driving forces constantly generated by the intrinsic attributes of the capitalist system." (Kornai, 2008, p.191) 
Besides the logical inconsistencies found in his work, Kornai draws attention to an interesting oxymoron, the concept of the "competitive equilibrium" (Kornai, 2005, pp.190-191). Particularly, he appears to be mainly concerned with the title of the concept rather than its content. Considering the GE as a closed axiomatic system in essence, he recognizes Debreu's work whose goal was to make his theoretical system just axiomatic. In the work of the Kornai, abstract theory and reality are two separate worlds while AE can be the link connecting them, by evaluating the accountability of theory. By no means does he consider the GE as a reference model, which surely contributed to modern investigations of Cournot's issue under newer conditions and dimensions. We argue that the AE theory could have been more successful in its own right, if it contained just the descriptive non-equilibrium model rather than incorporating a critique of the GE. For example, if Kornai had rephrased Cornout's original question under the conditions of his qualitatively new conceptual system, it could still have served as implicit criticism of the GE. In support of this argument, the AE is evidently not the GE's extension of nonequilibrium state, and vice versa, GE is not the equilibrium state of AE. Kornai obviously meant this when he wrote that the: "(...) $G E$ is a mathematical crystal, [which] cannot be improved" (Kornai, 1971, p. 203) while even Hahn concluded that it could not get shinier (Hahn, 1973, p.328).

Numerous economic intuitions and insights, for example highlighting the role of conflicts, which is now a popular topic in game theory research, were dominant in Kornai's AE theory. However, Kornai's hypotheses and assertions could not have gotten rigorous proofs. Additionally, they could not have become theorems mainly because of the underdeveloped level of methodology at that time. Using modern techniques, the conjectures and statements discussed in the AE could be verified.

Further, Kornai's (1971) criticism targeted specifically the economic assumptions and implications of GE while it did not deal with the assumption of irreversibility in the Arrow-Debreu model at all. Baumgärtner's (2005) findings deal exactly with this assumption, distinguishing between the temporary irreversibility and the thermodynamic irreversibility. The former's definition in the Arrow-Debreu model is presented in the following statement:

"[It] asserts the impossibility of two production possibility vectors which exactly cancel each other, in the sense that the outputs of one are exactly the inputs of the other" (Arrow and Debreu, 1954, p. 268) The concept of irreversibility is deeply rooted in laws of nature, more precisely in thermodynamics, which is the branch of physics that deals with the transformation of energy and material. So, in order to interpret the thermodynamic irreversibility in an economic model the interactions of the environment and the economy must be described by state variables according to physics principles. It is well known, chiefly from Samuelson's many works, that most economic models, such as the Neumann-model, do not satisfy these conditions. Baumgärtner's new approach has shown that the Arrow-Debreu concept of irreversibility, $\mathrm{Y} \cap(-\mathrm{Y})=(0)$, corresponds to the concept of temporary irreversibility but not to thermodynamic irreversibility. This, in turn, 
means that the concept of standard irreversibility in the Arrow-Debreu model is too weak to correspond to laws of nature. This is hardly surprising since the GE is imperfectly defined from the physics perspective, thus thermodynamic irreversibility not being a relevant characteristic of the model. Often neglecting reality, Arrow and Debreu were mainly interested in showing the existence of competitive equilibrium under the weakest possible conditions.

\section{Conclusions \& Discussion: New Developments}

Going through this rigorous critical comparison of the general equilibrium and the anti-equilibrium theories, one might get the impression that the critiques and ripostes do not really question the relevance of the discussed models. However, there is a gap in the literature regarding whether a synthesis between the two models is potentially feasible (Kornai, 1980; Punzo, 1989; Weintraub and Mirowsky, 1994).

The key to answer this question lies in using ex post and ex ante modelling philosophy in different combinations. While the former deals with the patterns of interconnections between variables that are acceptable according to observable reality, the latter concept represents abstract objects and structures. Ex-post models are descriptive and chiefly based on intuitive-inductive logical approaches. On the contrary, ex-ante models follow hypothetical-deductive approaches and are normative in nature (Kornai, 1971, p. 343). Theories are developed on the basis of functional analogy while the discussed models (variables, parameters etc.) are designed a priori. Ex-ante models do not primarily target the empirical validation of their expectations. Unlike the expost models, where the variables and parameters are always observable and measurable and their conclusions always carry on an empirical interpretation, potential solutions to the ex-ante models can be interpret only theoretically. Their main criterions are the immanent logical consistency and the Bourbakism-specific "theoretical purity", which does not require the empirical interpretability of its results. On the other hand, indispensable features of the ex-post models are a posteriori assumptions and the realism of their elements.

Naturally, the above-mentioned sterile differentiation is almost never clearly observable hindering a rigid categorisation of economic models. The scale of abstraction in their assumptions is what underlines the dominance of the one or the other type, making it too complicated to label research work as being chiefly ex-post or ex-ante. However, distinguishing between different theories and perceptions of economics based on this differentiation is feasible. For instance, it could be argued that in Kornai's work the ex-post approach is stronger while it less apparent in Arrow's work. Further, in Debreu's work the ex-ante approach is said to be quite dominant. Additionally, it can be claimed that classic economic models, with AE being one of them, rely heavily on the ex-post approach, while Wald's and Neumann's GE models and thus the GE mainly adopt an ex-ante philosophy. Leaving the issue of the reality of their assumptions aside, the relevance of both of them is also questionable. The GE 
is not the equilibrium state of $\mathrm{AE}$ and vice versa; the $\mathrm{AE}$ is not a nonequilibrium extension of the GE; which according to current knowledge implies that a synthesis of the two is not possible.

It is important to note that the different modelling philosophies are not strictly related to specific schools of thought and/or social systems. In neoclassical economics, we can find both ex-ante and ex-post approach dominated models. This does not contradict Kornai's remark that the core of the neoclassical theory is the GE. This statement even holds about the models dealing with comparisons of economic structure in capitalist and socialist societies. That is, both the $\mathrm{AE}$ and the GE are independent of economic schools, and could be politically neutral, as Kornai says.

Kornai's book published 2008 is "a deep interview with himself"; a presentation of a successful and fruitful carrier. However, besides the limelight of academic success, lack of understanding of the AE is evident in the book while the failure to influence substantially the economic thought is also discussed. In the light of modern developments, it appears that the superficial and harsh reviews actually prevented Kornai from elaborating a number of new ideas outlined in the Anti-equilibrium. Hahn placed his confidence in Debreu in that he would answer the critical questions raised by the AE theory, but he failed to provide constructive criticism of Kornai's work. Kornai also wonders about the motives and reasons for this harsh and fruitless debate and argues that Hahn could have published such a critique article mainly because he was not diplomatic. Others think that before publishing his AE theory, Kornai should have tested the followers of GE by publishing some of the main points of his criticism in leading international journals. We argue that publishing the AE exactly at the time when GE was popular and highly appreciated contributed to the debate being unproductive.

At that time, the authors of the GE theory were considered as potential Nobel laureates. The Royal Swedish Academy of Sciences has decided to award the Bank of Sweden Prize of Economic Sciences in Memory of Alfred Nobel to Kenneth Arrow and John R Hicks in 1972 and Gerard Debreu in 1983. The formers were awarded for their pioneering contributions to general equilibrium and welfare theories and the latter for his rigorous reformulation of the theory of general equilibrium.

Arrow, in his Nobel Memorial lecture noted that: “... even in the most strictly neoclassical version of price theory, it is not precisely true that prices alone are adequate information to the individual agents for the achievement of equilibrium, a point that will be developed later. One brand of criticism has put more stress on quantities themselves as signals; see especially the interpretation of Keynes by Leijonhufvud [1968, especially Chapter II]. More recently, the same argument has been advanced by Kornai [1971] from socialist experience. Nevertheless, while the criticisms are, in my judgment, not without some validity, they have not given rise to a genuine alternative model of detailed resource allocation. The fundamental question remains, how does an overall total quantity, say demand, as in the Keynesian model, get transformed into a set of signals and incentives for individual sellers?"(Arrow, 
1972, p.111) Evidently, he partly accepted Kornai's criticism, while Debreu did not mention it at all.

However, in the second half of the 1970's, several critiques of the GE model were published. According to them, the general equilibrium theory left out government, money, finance, monopoly, co-operation, expectation and change over time, and had nothing to say about unemployment, resources and income distribution, and inequality. Additionally it was claimed that it failed to describe the functions of actual markets. It was shown that such equilibrium was mathematically not impossible, as it heavily depends on full use of available resources according to the concept of Pareto efficiency. However, whether such equilibria could exist, even in mathematical models characterised by stability, is not yet known. Arrow's co-author Frank Hahn wrote that "the complete market hypothesis completely falsified" and Arrow added that "such a system could not exist". Hahn went even further by arguing that the conditions for general equilibrium turned out to be so demanding, that the Arrow-Debreu model was mostly useful as a refutation of the market's 'invisible hand'. According to Joseph Stiglitz, "in complete markets which operate in the absence of perfect information, any equilibrium could not be Pareto efficient." (Offer and Söderberg, 2016, pp.19-20) However, Leontief's critique, as cited in Offer and Söderberg (2016, p. 155), is apparently closer to Kornai's: "When I developed input-output analysis it was as a response to the weakness of classical-neoclassical supply and demand analysis.... I felt that general equilibrium theory does not see how to integrate the facts."

Debreu's Nobel Prize, awarded in 1983, fuelled a new debate about the validity of the GE prediction, which led to the foundation of modern theories regarding the concept of the markets' invisible hand. Debreu also contributed to the formulation of the Sonnenschein - Mantel - Debreu assertion, by demonstrating that the aggregation of individual choices is indeterminate. (Sonnenschein, 1973; Mantel, 1974; Debreu, 1972)

Recently, many Nobel laureates expressed serious doubts about the validity of the orthodox neoclassical theory ${ }^{20}$ and specifically, the ArrowDebreu general equilibrium model. They also provided many suggestions about improving the classic, economic models. Among them, Kornai (2014) has developed a new model in his newest book. His DRSE (Dynamism, Rivalry \& Surplus Economy) theory adopts the ex-post model philosophy; it radically rejects the ex-ante set of conditions adopted by the dominant neoclassical school and the stringent limits of equilibrium and defines its own premises for the functioning of capitalist economy. In other words, the DRSE theory represents an extremely novel trend among the various schools of economics. It is still only a verbally described model featuring the following supporting pillars of the capitalist system: dynamism, rivalry and the surplus economy. The model highlights the dominance of the surplus economy, the replacement

\footnotetext{
20 "In their Nobel Lectures, several NPWs stated, with all the authority of a newly minted NPW, that orthodox neoclassical theory was actually wrong, in whole or in part, on either empirical or theoretical grounds. Hayek, Simon, Solow, Haavelmo, Coase, North, Sen, Kahneman: all of them said that the theory could be wrong." (Offer and Söderberg, 2016, p.65)
} 
of oversupply by monopolistic competition, uncertainty over the volume of demand, Schumpeterian innovation, dynamism, technological progress, creative destruction and increasing return to scale with rivalry between producers and service providers for markets.

In our recent paper (Móczár, 2015), we aim to examine whether the DRSE theory can be formulated as a formal mathematical model. We choose a special route to do this: first, we explore the unrealistic ex-ante assumptions of general equilibrium theory (Walras, 1987; Neumann, 1945). Then, we establish some of the possible connections between the features of the DRSE theorem, including the crucial condition that, just like in any biological evolutionary process, there is no fixed steady state in the such processes followed by market economy, not even as a point of reference. General equilibrium theory and the DRSE theory are compared and contrasted in the framework of Schumpeterian evolutionary economics.

Kornai (2014) made several different proposals, which potentially lead to the general mathematical model of the DRSE theory. In the light of Móczár's paper (2015), the model presents an ergodic, dynamic system which has a constantly changing equilibrium point that can never be reached. Additionally, it includes a system of constraints expressing the "drivers" that ensure the functioning of the surplus economy. Undoubtedly, we could get closer to the formulation of the model if Schumpeter had expressed his evolutionary theory in mathematical formulas as well. However, there are many disequilibrium models in the literature, which have attempted to provide a modern overview of Schumpeterian dynamics. Hopefully, the work by Bénassy (2005), Punzo (2001) and Sinai (1994), could certainly get us closer to a specific mathematical formulation of the DRSE model.

\section{References}

Arrow KJ, Block HD, and Hurwicz L (1958) On the Stability of the Competitive Equilibrium, Part I. Econometrica, 26: 297-305.

Arrow KJ, Debreu G (1954) Existence of an Equilibrium for a Competitive Economy, Econometrica, 22: 265-290.

Arrow KJ, Block HD, and Hurwicz L (1959) On the Stability of the Competitive Equilibrium, Part II. Econometrica, 27: 82-109.

Arrow KJ, Hahn HF (1971): General Competitive Analysis. San Francisco: Holden Day.

Baumgartner S (2005): Temporal and thermodynamic irreversibility in production theory. Economic Theory, 26: 725-728.

Benassy JP (2005): The Macroeconomics of Imperfect Competition and Non-clearing Market. Cambridge, MA: MIT-Press.

Bródy A (1980): Cycle and Control (In Hungarian). Budapest: Közgazdasági és Jogi Könyvkiadó.

Cassel G (1932) The Theory of Social Economy. New York: Harcourt Brace.

Chiarella C, Flaschel P (2000) The Dynamics of Keynesian Monetary Growth. Cambridge: Cambridge University Press. 
Cournot AA, Fisher I (1897) Researches into the Mathematical Principles of the Theory of Wealth. London: Macmillan Co.

Day RH (1984) Disequilibrium Economic Dynamics. Journal of Economic Behaviuor and Organization, 5: 57-76.

Debreu G (1952): A Social Equilibrium Existence Theorem. Proceedings of the National Academy of Sciences, USA, 38: 886-893.

Debreu G (1959) Theory of Value (An Axiomatic Analysis of Economic Equilibrium). Wiley, New York.

Debreu G (1972) Excess Demand Functions. Journal of Mathematical Economics, 1: $15-23$.

Debreu G (1991) The Mathematization of Economic Theory. American Economic Review, 81: 1-7.

Dornbush R (1976) Expectations and Exchange Rate Dynamics. The Journal of Political Economy, 84(6): 1161-1176

Gale D (1973) The Law of Supply and Demand. Mathematica Scandinavica, 37: 155169.

Hahn HF (1973) The Winter of our Discontent. Economica, 32: 322-330.

Hahn HF (2005) Kornai vs Hahn, e-mail changing, Cambridge-Budapest.

Hahn HF, Petri F (eds.) (2003) General Equilibrium (Problems and Prospects). London: Routledge.

Hahn HF, Solow R (1997) A Critical Essay on Modern Macroeconomic Theory. Cambridge, MA: MIT Press.

Hicks J (1939) Value and Capital (An inquiry into some fundamental principles of economic theory), London: Oxford University Press.

Hicks J (1989) A market theory of money. London: Oxford University Press.

Hildenbrand W (1983) On the „Law of Demand”. Econometrica, 4: 997-1020.

Hildenbrand W (1994) Market Demand: Theory and Empirical Evidence. Princeton: Princton University Press.

Iwai K (2001) A Disequilibrium Theory of Long-run Profits: Schumpeterian Dynamics. In: Punzo L (ed.) Cycles, Growth and Structural Change. London: Routledge.

John R (1999) Abraham Wald's equilibrium existence proof reconsidered. Economic Theory, 13: 417-428.

Keynes, JM (1936) The general theory of interest, employment and money. London: MacMillan

Koopmans TC (1951) Analysis of production as an Efficient Combination of Activities, In: Koopmans, TC (ed.) Activity Analysis of Production and Allocation. Cowles Commission Monograph, 13. New York: John Wiley and Son.

Kornai J (1971): Anti-equilibrium (On Economic Systems Theory and The Tasks of Research), Amsterdam: North-Holland Publishing Company.

Kornai J (1980): Economics of Shortage. Amsterdam: North-Holland Publishing Company.

Kornai J (2005) By Force of Thought (Irregular Memoirs of an Intellectual Journey), Cambridge, MA: MIT Press.

Kornai J (2008) By force of thought: irregular memoirs of an intellectual journey. USA: MIT Press Books.

Kornai J (2014) Dynamism, Rivalry and The Surplus Economy (Two Essays on the Nature of Capitalism). New York: Oxford University Press.

Kornai J, Lipták T (1965) Two-level Planning, Econometrica, 33: 141-169. 
Lakatos I (1981) Proofs and Refutations: The Logic of Mathematical Discovery. Cambridge: Cambridge University Press.

Lyapunov A (1907) Probleme general de la stabilite du movement. Annales de Toulouse, 9: 2.

Makarov VL, Rubinov AM (1977) Mathematical Theory of Economic Dynamics and Equilibria. New York: Springer-Verlag.

Mantel RR (1974): On the characterizations of aggregate excess demand. Journal of Economic Theory, 7: 348-353.

Mass-Colell A (1986): Notes on Price and Quantity Tatonnement Dynamics, In: Sonnenschein H (ed.): Models of Economic Dynamics, New York: SpringerVerlag.

Mc Kenzie L (1954) On equilibrium in Graham's model of world trade and other competitive systems. Econometrica, 12: 147-161.

Metzler LA (1945) Stability of Multiple Markets: The Hicks Conditions. Econometrica, 13: 277-292.

Móczár J (1995) Reducible von Neumann models and uniqueness. Metroeconomica, 46: $1-15$.

Móczár J (2015) Kornai's DRSE Theory Versus General Equilibrium Theory. Public Finance-Journal Public Finance, 60: 194-211.

Móczár J, Tsukui J (1992) Balanced and unbalanced growth paths in a decomposable economy: contributions to the theory of multiple turnpikes. Economic Systems Research, 3: 211-222.

Nash J (1950) Equilibrium Points in N-Person Games. Proceedings of the National Academy of Sciences, USA, 36: 48-49.

Negishi T (1962) The stability of a competitive economy: a survey article. Econometrica, 30: 635-669.

Offer A, Söderberg G (2016) The Nobel Factor: The Prize in Economics, Social Democracy, and the Market Turn. USA: Princeton University Press.

Patinkin D (1948) Relative Prices, Say's Law, and the Demand for Money. Econometrica, 16: 135-154.

Punzo L (1989) Von Neumann and Karl Menger's Mathematical Colloquium. In: Dore MS, Chakravarty S, Goodwin R (eds.): John von Neumann and Modern Economics. Oxford: Clarendon Press.

Punzo L (1991) The School of Mathematical Formalism and the Viennese Circle of Mathematical Economists. Journal of the History of Economic Thought, 13: 118.

Punzo L (2001) Cycles, Growth and Structural Change. London: Routledge.

Samuelson PA (1943): Dynamics, Statics, and the Stationary States. Review of Economics and Statistics, 25: 58-68.

Samuelson PA (1947) Foundations of Economic Analysis. Cambridge MA: Harvard University Press.

Scarf H (1960) Some Examples of Global Instability of the Competitive Equilibrium. International Economic Review, September: 157-172.

Schlesinger K (1935) Uber die Produktionsgleichungen der okonomischen Wertlehre. Ergebnisse eines mathematischen Kolloquiums, 6: 10-11.

Shafer W, Sonnenschein H (1982) Market demand and excess demand functions, In: Arrow KJ, Intriligator MD (eds.): Handbook of Mathematical Economics, Amsterdam: North-Holland.

Sinai YAG (1994) Topics in Ergodic Theory. Princeton: Princeton University Press.

Smithies A (1942) The Stability of Competitive Equilibrium. Econometrica, 10: 258274. 
Sonnenschein HF (1972) Market Excess Demand Functions. Econometrica, 40: 549563.

Sonnenschein HF (1973) Do Walras' Identity and Continuity Characterize the Class of Community Excess Demand Functions? Journal of Economic Theory, 6: 345354.

Tsukui J, Murakami Y (1979) Turnpike Optimality in Input-Output Systems. Amsterdam: North-Holland.

Von Neumann J, Morgenstern O (1945) Theory of games and economic behavior. Bull. Amer. Math. Soc, 51(7): 498-504.

Wald A (1935): Über die eideutige positive Lösbarkeit der neuen Produktiongleischungen. Ergebnisse eines matematischen Kolloquiums, 6: 12-20.

Wald A (1936) Über die produktions gleichungen der ökonomischen Wertlehre (II. Mitteilung) [On the Production Equations of Economic Value Theory (Part 2)]. Ergebnisse eines matematischen Kolloquiums, 7: 1-6.

Wald A, (1951) On some systems of equations of mathematical economics. Econometrica:, pp.368-403.

Walras L (1874) Eléments d'économie politique pure ou théorie de la richesse sociale (Elements of Pure Economics, or the theory of social wealth). Lausanne, Paris: Pichon et Durand-Auzias.

Weintraub ER (1979) Microfoundations. Cambridge: Cambridge University Press.

Weintraub ER (1979) How Economics Became Mathematical Science. Cambridge: Cambridge University Press.

Weintraub ER, Mirowski G (1994) The Pure and the Applied: Bourbakism Comes to Mathematical Economics. Science in Context, 2: 245-272.

Wittgenstein L (1922) Tractatus Logico-Philosophicus (With an Introduction by Bertrand Russell), New York: Harcourt Brace Co. 
